\title{
Human leukocyte antigen class II variants and adult-onset asthma: does occupational allergen exposure play a role?
}

\author{
Lidwien A.M. Smit, David P. Strachan, Roel Vermeulen, Paul I.W. de Bakker, \\ Florence Demenais, Orianne Dumas, Anne-Elie Carsin, Paul Cullinan, \\ Ivan Curjuric, Rebecca E. Ghosh, Dick Heederik, Medea Imboden, Deborah Jarvis, \\ Mark Lathrop, Nicole Le Moual, Amar Mehta, David Miedinger, Torben Sigsgaard, \\ Valérie Siroux, David Vernez, Jan Paul Zock, Francine Kauffmann, \\ Nicole Probst-Hensch, Manolis Kogevinas and Emmanuelle Bouzigon
}

Affiliations: For the authors' affiliations see the Acknowledgements section.

Correspondence: Lidwien A.M. Smit, IRAS, Division Environmental Epidemiology, Utrecht University, PO Box 80178, 3508 TD Utrecht, The Netherlands. E-mail: l.a.smitauu.nl

ABSTRACT Recently, a locus centred on rs9273349 in the HLA-DQ region emerged from genome-wide association studies of adult-onset asthma. We aimed to further investigate the role of human leukocyte antigen (HLA) class II in adult-onset asthma and a possible interaction with occupational exposures.

We imputed classical HLA-II alleles from 7579 single-nucleotide polymorphisms in 6025 subjects (1202 with adult-onset asthma) from European cohorts: ECRHS, SAPALDIA, EGEA and B58C, and from surveys of bakers and agricultural workers. Based on an asthma-specific job-exposure matrix, 2629 subjects had ever been exposed to high molecular weight (HMW) allergens. We explored associations between 23 common HLA-II alleles and adult-onset asthma, and tested for gene-environment interaction with occupational exposure to HMW allergens. Interaction was also tested for rs 9273349.

Marginal associations of classical HLA-II alleles and adult-onset asthma were not statistically significant. Interaction was detected between the $D P B 1^{*} 03: 01$ allele and exposure to HMW allergens $(\mathrm{p}=0.009)$, in particular to latex $(\mathrm{p}=0.01)$. In the unexposed group, the $D P B 1^{\star} 03: 01$ allele was associated with adult-onset asthma (OR 0.67, 95\%CI 0.53-0.86). HMW allergen exposures did not modify the association of rs9273349 with adult-onset asthma.

Common classical HLA-II alleles were not marginally associated with adult-onset asthma. The association of latex exposure and adult-onset asthma may be modified by $D P B 1^{\star} 03: 01$.

@ERSpublications

In an analysis involving $>6000$ European adults, classical HLA-II alleles were not associated with adult-onset asthma http://ow.ly/xTdFm

This article has supplementary material available from www.erj.ersjournals.com

Received: April 092014 | Accepted: June 092014 | First published online: July 172014

Conflict of interest: Disclosures can be found alongside the online version of this article at www.erj.ersjournals.com

Copyright @ERS 2014 


\section{Introduction}

The highly polymorphic human leukocyte antigen (HLA) class II molecules (DR, DQ and DP) are expressed on the surface of antigen-presenting cells, where they present peptides of exogenous origin to T-cell receptors on $\mathrm{CD}^{+}$cells. Because of the pivotal role of HLA-II molecules in the recognition of allergenderived peptides, HLA alleles have been extensively studied in hypothesis-driven candidate gene association studies for allergic sensitisation and asthma [1,2]. HLA is also the most evaluated genetic risk factor for occupational asthma. Although results were inconsistent, a role of the HLA-DQB1 locus in occupational asthma aetiology is plausible [3].

Evidence from several independent genome-wide association studies (GWAS) lend further support to the involvement of HLA-II loci in asthma, allergic sensitisation and increased total IgE level [4-11]. The GABRIEL consortium carried out the largest asthma GWAS to date, by genotyping 10365 asthma patients and 16110 controls recruited from 23 studies [4]. A locus centred on rs9273349 in the HLA-DQ region showed strong evidence of association in the overall sample $\left(\mathrm{p}=7 \times 10^{-14}\right.$; OR for C allele 1.18). This was the only single-nucleotide polymorphism (SNP) with genome-wide significance for asthma with onset at 16 years of age or older $\left(\mathrm{p}=4 \times 10^{-8}\right.$; OR 1.26). Interestingly, a more pronounced effect of rs 9273349 was observed in later-onset asthma than in childhood-onset asthma, although the difference was not significant. A recent GWAS replicated the association of this SNP with asthma and also reported notably stronger associations in the adult compared with the childhood population [6].

It has been suggested that investigating gene-environment interactions may help to understand associations of HLA with asthma that were identified by GWAS [12]. Indeed, the strength of the association of HLA variants with asthma could depend on concomitant environmental exposures. Considering individuals' age of asthma onset can be instrumental in revealing gene-environment interactions [13, 14]. The agedependent effects that were observed in GWAS may provide clues to the role of HLA, because late-onset asthma may have different underlying environmental risk factors than childhood asthma. In adults, occupational exposures are an important cause of incident asthma, with a population attributable risk of around 15\% [15-17]. Investigating the effect of gene-environment interactions between HLA alleles and occupational exposures on asthma risk might reveal mechanisms mediated by specific HLA alleles and triggered by occupational sensitisers such as latex, flour or animal proteins.

The aim of the present study is to further investigate the role of HLA-II in adult-onset asthma in a metaanalysis of population-based and workforce-based studies. We imputed classical HLA-II alleles from 7579 SNPs, allowing an evaluation of association between HLA-II alleles and adult-onset asthma. In addition, we explored whether occupational exposure to high molecular weight (HMW) allergens modifies the effect of imputed HLA-II alleles and the rs9273349 SNP in the HLA-DQ region that emerged from the GABRIEL study on adult-onset asthma.

\section{Methods}

Population

We studied all European cohorts that were included in GABRIEL with detailed data available on occupational history: EGEA [18, 19], SAPALDIA [20, 21] and ECRHS [15, 22] (referred to as the "ESE cohorts") [23], the British 1958 birth cohort (B58C) [16, 24], and industrial cohorts of Dutch and Danish agricultural workers (AGRI) [25], and Dutch bakery workers (BAKERY) [26]. We included nested asthma case-control samples (SAPALDIA, ECRHS, AGRI and BAKERY) as previously described [4], and all subjects from EGEA and B58C with data available on genome-wide genotyping, occupational history and adult-onset asthma. Adult-onset asthma was defined as ever having had asthma with an onset $\geqslant 16$ years [4]. Subjects who had never had asthma were used as the reference group. Ethical approval was obtained for each cohort from the appropriate institutional ethics committee. Detailed cohort descriptions are given in the online supplementary material.

Support statement: This gene-environment interaction analysis was supported by IAGO ANR-2010-PRSP-003, and by the Netherlands Organisation for Scientific Research (NWO)/French Ministry of Foreign and European affairs Van Gogh programme for French-Dutch cooperation. Genotyping of the ESE and industrial cohorts, and part of B58C was funded by the GABRIEL asthma genetic consortium supported by a contract from the European Commission (018996) and grants from the French Ministry of Research, the Wellcome Trust (WT084703MA), Asthma UK and The COLT Foundation. For B58C, Asthma UK provided funding for the asthma-specific job-exposure matrix coding of occupational exposures and investigation of their associations with asthma, and the COLT Foundation provided funding for extension of this work to look at other allergic outcomes. Further sources of funding for the participating cohorts are given in the online supplementary material. None of the funders had any role in study design, data collection and analysis, or preparation of the manuscript. 


\section{Genotyping}

Genome-wide genotyping was conducted using the Human610 quad array panel (Illumina, San Diego, CA, USA) [4]. More details on genotyping of B58C are given in the online supplementary material. We investigated whether the association of the GABRIEL main signal (rs9273349) with adult-onset asthma was modified by occupational exposure. For completeness regarding GABRIEL HLA-II results, we further selected a subset of 18 tag SNPs using Haploview (Broad Institute, Cambridge, MA, USA) [27], and tested for geneenvironment interaction with occupational exposure to HMW allergens (online supplementary material).

\section{Imputation of classical HLA-II alleles}

For all cohorts in the present analysis, we used 7579 SNPs of the extended major histocompatibility complex (MHC) (20-40 Mbp on chromosome 6) to impute classical HLA types for class II loci at four-digit resolution. Imputations were performed using BEAGLE software (University of Washington, Seattle, WA, USA) on the basis of haplotype patterns in 2767 unrelated individuals of European descent (this reference panel includes B58C subjects), as described previously [28]. Concordance between imputed data and genotyping (Dynal RELI SSO assays; Invitrogen, Carslbad, CA, USA) [29] was assessed for DRB1 and DQB1 alleles in the $2310 \mathrm{~B} 58 \mathrm{C}$ subjects included in the present paper who were not part of the reference panel for the BEAGLE imputations (online supplementary table E1). Imputation quality was generally high for common alleles $\left(\mathrm{r}^{2}>0.8\right)$. Pairwise linkage disequilibrium measures $\left(\mathrm{D}^{\prime}\right.$ and $\left.\mathrm{r}^{2}\right)$ between classical HLA-II alleles and rs9273349 and the other 18 SNPs were estimated using Haploview (tables E2 and E3) [27].

\section{Occupational exposure to HMW allergens}

Occupational exposure assessment is described in detail in the online supplementary material. Briefly, in all cohorts, occupations were linked to an asthma-specific job-exposure matrix with a local expert reevaluation step [19]. We only considered seven HMW allergens high-risk substances (namely animal proteins, fish or shellfish, mites, latex, flour, other plant antigens, and enzymes) that may cause asthma through a similar, predominantly IgE-associated mechanism. Subjects who were ever exposed to any of the seven HMW allergens were classified as "exposed". The "unexposed" reference group consisted of subjects who were never exposed to any of the high-risk or low-risk jobs.

\section{Statistical analysis}

The ESE cohorts were pooled to increase statistical power and to avoid convergence problems, as was done before with EGEA and ECRHS data [30]. Raw data from B58C were not available for pooled analysis. We tested association of 23 common classical HLA-II alleles with allele frequency $>5 \%$ in each population with adult-onset asthma, assuming an additive genetic model. In ESE cohorts, population admixture was taken into account by including principal components for within-Europe diversity as covariates in the association analysis. Genetic effects were estimated in each cohort separately, stratified by exposure status. The overall (exposure-adjusted) gene effect was estimated by standard fixed-effects meta-analysis of ESE exposed, ESE unexposed, B58C exposed and B58C unexposed subjects. To evaluate gene-environment interaction, results in exposed and unexposed subjects from ESE and B58C were combined through fixed-effects meta-analysis to obtain odds ratios in the exposed and unexposed groups. Both the standard 1 degree of freedom (df) test of gene-environment interaction and the $2 \mathrm{df}$ joint test of marginal genetic effects and gene-environment interaction were performed, the latter being generally considered to have greater power than the marginal test when the genetic effect is only expressed in exposed individuals [31,32]. Additional analyses were performed by including the industrial cohorts in the meta-analysis of HMW allergen exposed workers, and performing the joint test and test for interaction. The industrial cohorts were not included to evaluate the marginal genetic effect because all subjects in these cohorts were exposed, so the interaction effect cannot be assumed to be independent of the exposed-only odds ratio. We did not adjust for multiple testing because of the prior evidence of HLA-II involvement in several GWAS. Instead, we used a p-value threshold of $<0.01$ for the test of marginal association, joint test and test for interaction. More details are given in the online supplementary material.

\section{Results}

Descriptive characteristics of the HMW allergen exposed and unexposed study subjects are summarised in table 1. Subjects with childhood-onset asthma $(n=685)$ or missing age of onset $(n=59)$ were excluded from data analysis, leaving data from 6025 subjects for analysis. Latex was the predominant occupational exposure among subjects from the general population cohorts who were classified as HMW allergen exposed (from 64\% exposed in B58C to 84\% in SAPALDIA). Occupational exposure to HMW allergens was positively associated with adult-onset asthma in each of the four general population cohorts, with a fixedeffects summary odds ratio of 1.33 (95\% CI 1.11-1.60) (fig. 1). 
TABLE 1 Descriptive characteristics of the study cohorts by exposure status

\section{HMW allergen exposed}

Subjects $n$

Age years

Males \%

Asthma $\mathrm{n}$

Adult-onset asthma

No asthma $n$

HMW allergen exposures

Latex

Animal proteins

Fish or shellfish

Flour

Other plant antigens

Mite and insect antigens

Enzymes

\section{HMW allergen unexposed}

\section{Subjects $n$}

Age years

Males \%

Asthma $\mathrm{n}$

Adult-onset asthma

No asthma
EGEA

SAPALDIA

$\begin{array}{cc}192 & 121 \\ 43.4 \pm 14.0 & 48.6 \pm 10.0 \\ 29 & 12 \\ 85 & 53 \\ 35(41) & 37(70) \\ 107 & 68\end{array}$

\section{$129(67)$}

$33(17)$

$1(0.5)$

$13(6.8)$

$5(2.6)$

$20(10)$

$9(4.7)$

$\begin{array}{cc}724 & 669 \\ 42.0 \pm 15.1 & 53.7 \pm 10.7 \\ 39 & 48 \\ 294 & 276 \\ 94(32) & 162(59) \\ 430 & 393\end{array}$

ECRHS

\section{$102(84)$}

$1(0.8)$

$0(0.0)$

$7(5.7)$

$3(2.4)$

$10(8.3)$

$5(4.1)$

393
B58C

AGRI

BAKERY

$\begin{array}{cccc}214 & 1337 & 683 & 263 \\ 41.5 \pm 7.1 & 45.2 \pm 0.4 & 28.6 \pm 12.6 & 39.9 \pm 10.8 \\ 14 & 33 & 83 & 95 \\ 82 & 216 & 256 & 136 \\ 59(72) & 124(57) & N A^{\#} & N A^{\#} \\ 132 & 1121 & 427 & 127 \\ & & & \\ 161(75) & 853(64) & 0(0) & 0(0) \\ 15(7.0) & 198(15) & 475(70) & 0(0) \\ 1(0.4) & 19(1.4) & 0(0) & 0(0) \\ 8(3.7) & 82(6.1) & 57(8.3) & 263(100) \\ 4(1.9) & 169(13) & 143(21) & 0(0) \\ 30(14) & 183(14) & 66(9.7) & 0(0) \\ 10(4.7) & 66(4.9) & 0(0) & 263(100)\end{array}$

Data are presented as mean \pm SD or $\mathrm{n}(\%)$, unless otherwise stated. HMW: high molecular weight; NA: not available. ${ }^{\#}$ : age of asthma onset is not available in the industrial cohorts. a)

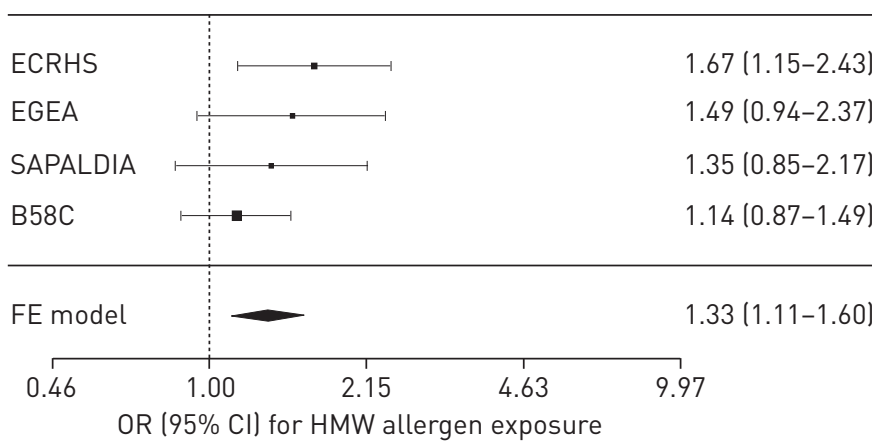

c)

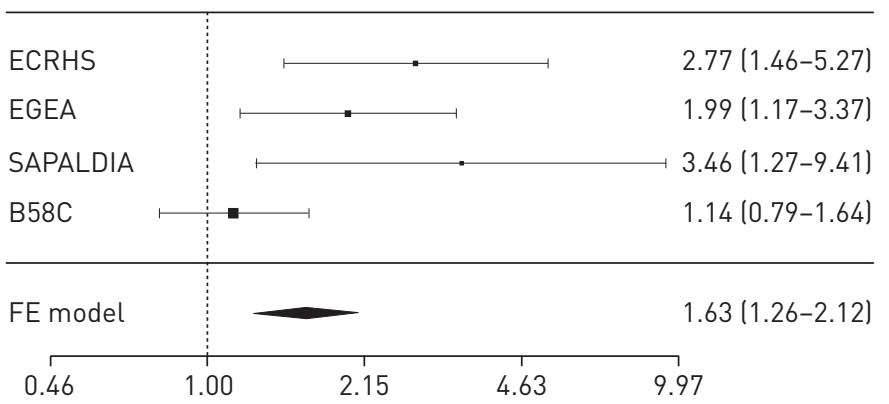

b)

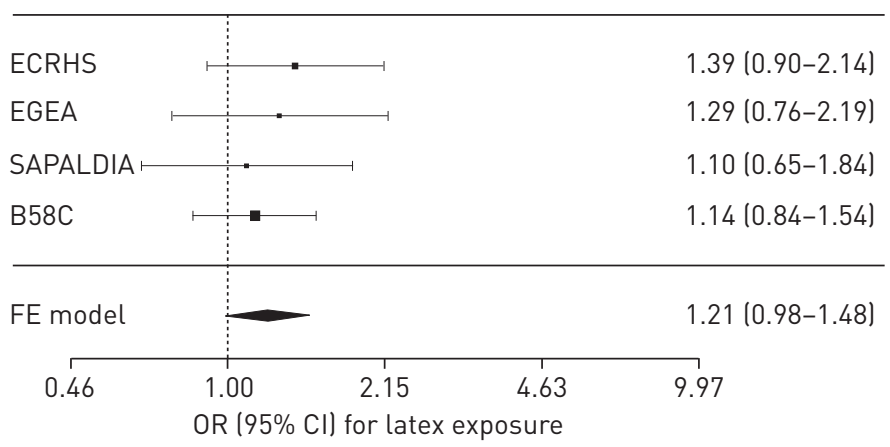

OR $(95 \% \mathrm{Cl})$ for non-latex HMW allergen exposure

FIGURE 1 Forest plot of odds ratios and 95\% confidence intervals for the association of occupational exposure to a) high molecular weight (HMW) allergens,

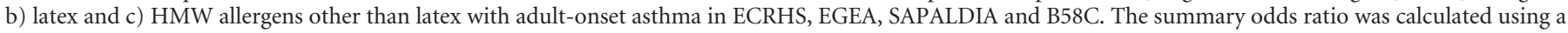
fixed-effects meta-analysis (FE model). 
TABLE 2 Association of imputed classical human leukocyte antigen (HLA) class II alleles, rs9273349, and adult-onset asthma in all ESE and B58C subjects, and according to ever having been exposed to occupational high molecular weight (HMW) allergens

\begin{tabular}{|c|c|c|c|c|c|c|}
\hline \multirow[t]{2}{*}{ HLA-II allele } & \multirow[t]{2}{*}{$\mathrm{AF}^{\#}$} & \multirow[t]{2}{*}{ All subjects ${ }^{\pi}$} & \multirow{2}{*}{$\begin{array}{l}\text { HMW allergen } \\
\text { exposed }^{+}\end{array}$} & \multirow{2}{*}{$\begin{array}{l}\text { HMW allergen } \\
\text { unexposed }\end{array}$} & \multicolumn{2}{|c|}{ p-value } \\
\hline & & & & & Joint test & Interaction \\
\hline DRB1*01:01 & 9.4 & $0.83(0.68-1.01)$ & $0.83(0.57-1.21)$ & $0.83(0.66-1.04)$ & 0.18 & 0.99 \\
\hline DRB1*03:01 & 12.6 & $1.09(0.92-1.29)$ & $1.05(0.79-1.40)$ & $1.11(0.91-1.36)$ & 0.52 & 0.75 \\
\hline DRB1*04:01 & 9.9 & $1.10(0.91-1.33)$ & $1.11(0.80-1.55)$ & $1.10(0.87-1.38)$ & 0.56 & 0.94 \\
\hline DRB1*07:01 & 13.3 & $1.04(0.89-1.23)$ & $1.12(0.84-1.49)$ & $1.01(0.83-1.23)$ & 0.73 & 0.58 \\
\hline DRB1*15:01 & 12.5 & $0.88(0.74-1.04)$ & $0.88(0.65-1.20)$ & $0.88(0.72-1.07)$ & 0.35 & 0.98 \\
\hline DQA1*01:01 & 15.1 & $0.91(0.78-1.06)$ & $0.97(0.72-1.31)$ & $0.88(0.73-1.06)$ & 0.44 & 0.59 \\
\hline DQA1*01:02 & 18.4 & $0.91(0.79-1.05)$ & $0.95(0.73-1.23)$ & $0.90(0.76-1.06)$ & 0.45 & 0.73 \\
\hline DQA1*01:03 & 6.8 & $0.81(0.65-1.01)$ & $0.75(0.49-1.16)$ & $0.83(0.64-1.07)$ & 0.17 & 0.71 \\
\hline DQA1*02:01 & 13.4 & $1.04(0.88-1.22)$ & $1.11(0.83-1.49)$ & $1.01(0.83-1.23)$ & 0.74 & 0.57 \\
\hline DQA1*03:01 & 18.6 & $1.09(0.95-1.26)$ & $1.06(0.82-1.36)$ & $1.11(0.93-1.32)$ & 0.41 & 0.78 \\
\hline DQA1*05:01 & 25.1 & $1.12(0.99-1.27)$ & $1.04(0.83-1.30)$ & $1.16(1.00-1.34)$ & 0.12 & 0.42 \\
\hline DQB1*02:01 & 17.8 & $1.06(0.92-1.22)$ & $1.09(0.85-1.41)$ & 1.05 (0.89-1.24) & 0.63 & 0.78 \\
\hline DQB1*03:01 & 19.1 & $1.12(0.98-1.28)$ & $1.07(0.84-1.38)$ & $1.14(0.97-1.33)$ & 0.23 & 0.72 \\
\hline DQB1*03:02 & 10.6 & $1.08(0.91-1.29)$ & $1.18(0.86-1.61)$ & $1.04(0.85-1.29)$ & 0.53 & 0.54 \\
\hline DQB1*05:01 & 12.3 & $0.89(0.75-1.06)$ & $0.98(0.71-1.35)$ & $0.86(0.70-1.06)$ & 0.38 & 0.51 \\
\hline DQB1*06:02 & 12.0 & $0.90(0.76-1.06)$ & $0.92(0.67-1.25)$ & $0.89(0.73-1.09)$ & 0.48 & 0.87 \\
\hline$D Q B 1 * 06: 03$ & 6.3 & $0.80(0.64-1.01)$ & $0.79(0.51-1.23)$ & $0.81(0.62-1.06)$ & 0.20 & 0.93 \\
\hline DPA1*01:03 & 18.8 & $0.94(0.80-1.10)$ & $0.92(0.70-1.21)$ & $0.95(0.78-1.15)$ & 0.75 & 0.86 \\
\hline$D P A 1 * 02: 01$ & 14.9 & $0.96(0.81-1.14)$ & $1.06(0.79-1.43)$ & $0.92(0.75-1.12)$ & 0.66 & 0.42 \\
\hline$D P B 1 * 02: 01$ & 13.4 & $1.19(1.02-1.39)$ & $1.02(0.76-1.38)$ & $1.25(1.05-1.50)$ & 0.04 & 0.25 \\
\hline DPB1*03:01 & 10.3 & $0.80(0.65-0.97)$ & $1.08(0.77-1.49)$ & $0.67(0.53-0.86)$ & 0.007 & 0.03 \\
\hline DPB1*04:01 & 42.4 & $1.03(0.92-1.15)$ & $1.02(0.83-1.25)$ & 1.03 (0.90-1.18) & 0.87 & 0.94 \\
\hline DPB1*04:02 & 11.1 & $1.01(0.85-1.21)$ & $0.94(0.68-1.29)$ & $1.05(0.84-1.30)$ & 0.84 & 0.58 \\
\hline rs9273349 T & 40.8 & $0.82(0.72-0.93)$ & $0.81(0.64-1.03)$ & $0.82(0.71-0.95)$ & 0.009 & 0.95 \\
\hline
\end{tabular}

Data are presented as OR $(95 \% \mathrm{CI})$ unless otherwise stated. AF: allele frequency. ${ }^{*}$ : weighted average in ESE and $\mathrm{B} 58 \mathrm{C} ;{ }^{\bullet}: \mathrm{n}=5079 ;{ }^{+}: \mathrm{n}=1683$; s: $n=3396$. Bold face indicates $p<0.05$.

Table 2 shows results from association tests of 23 imputed classical HLA-II alleles, rs9273349 C/T, and adult-onset asthma in the ESE and B58C cohorts. Marginal associations of HLA-II alleles were not statistically significant $(\mathrm{p}>0.01)$ but $\mathrm{rs} 9273349$ was, as expected, significantly associated with adult-onset asthma (OR for $\mathrm{T}$ allele 0.82, $\mathrm{p}=0.002$ ).

Association between rs9273349 and adult-onset asthma was similar in exposed and unexposed individuals (test for gene-environment interaction $\mathrm{p}=0.95$ ). For $D P B 1^{*} 03: 01$, the joint test was statistically significant $\left(\mathrm{p}=0.007\right.$, interaction $\mathrm{p}=0.03$ ). In unexposed individuals, $D P B 1^{\star} 03: 01$ was associated with a decreased risk of adult-onset asthma (OR 0.67, $\mathrm{p}=0.002$ ), but not in exposed subjects (OR 1.08, p=0.64). Study-specific estimates showed that the interaction was driven by the ESE cohorts (OR for exposed 1.34, $\mathrm{p}=0.20$; OR for unexposed 0.62, $\mathrm{p}=0.0009)$. In ESE subjects carrying at least one $D P B 1^{\star} 03: 01$ allele, the proportion of subjects with adult-onset asthma was higher in those exposed to occupational HMW allergens (35.6\%) and lower in the unexposed (15.0\%), compared with the same groups in ESE noncarriers $(28.4 \%$ and $22.2 \%$ in exposed and unexposed, respectively; fig. E1). Thus, in these cohorts, a stronger association between adultonset asthma and occupational HMW allergens was detected in carriers of at least one $D P B 1^{*} 03: 01$ allele (OR 3.13, 95\% CI 1.87-5.23) than in noncarriers (OR 1.39, 95\% CI 1.08-1.81). In B58C, DPB1*03:01 was not associated with asthma, whichever the exposure status (OR exposed $0.84, \mathrm{p}=0.48$; OR unexposed 0.89 , $\mathrm{p}=0.62$ ). Associations of $D P B 1^{\star} 03: 01$ and rs9273349 with adult-onset asthma were independent: the effect of each genetic polymorphism did not change when both were jointly included in a multiple regression model.

In the HMW allergen exposed industrial cohorts (meta-analysis of AGRI and BAKERY), DPB1 ${ }^{\star 03: 01}$ was not associated with asthma (table 3). However, the test for gene-environment interaction between $D P B 1^{\star} 03: 01$ and HMW exposure was more significant after including the industrial cohorts together with the population-based cohorts in the analysis $(\mathrm{p}=0.009)$. The association of allele $D Q B 1^{\star} 06: 02$ with asthma $(p=0.007)$ was restricted to the industrial cohorts, with a similar effect in agricultural workers (OR 0.72 , $\mathrm{p}=0.05)$ and bakery workers (OR $0.65, \mathrm{p}=0.07)$. 
TABLE 3 Association of imputed classical human leukocyte antigen (HLA) class II alleles, rs9273349, and adult-onset asthma in the industrial cohorts of agricultural workers and bakery workers, all subjects ever exposed to occupational high molecular weight (HMW) allergens (industrial cohorts, ESE and B58C) and unexposed subjects

\begin{tabular}{|c|c|c|c|c|c|c|}
\hline \multirow[t]{2}{*}{ HLA-II allele } & \multirow[t]{2}{*}{$A F^{\#}$} & \multirow{2}{*}{$\begin{array}{l}\text { Industrial HMW } \\
\text { allergen exposed only }\end{array}$} & \multirow{2}{*}{$\begin{array}{c}\text { All HMW allergen } \\
\text { exposed }^{+}\end{array}$} & \multirow{2}{*}{$\begin{array}{l}\text { HMW allergen } \\
\text { unexposed }^{\S}\end{array}$} & \multicolumn{2}{|c|}{ p-value } \\
\hline & & & & & Joint test & Interaction \\
\hline DRB1*01:01 & 9.4 & $0.96(0.70-1.31)$ & $0.90(0.71-1.15)$ & $0.83(0.66-1.04)$ & 0.21 & 0.62 \\
\hline DRB1*03:01 & 13.0 & $1.30(1.01-1.68)$ & $1.18(0.97-1.43)$ & $1.11(0.91-1.36)$ & 0.12 & 0.68 \\
\hline DRB1*04:01 & 10.0 & $0.93(0.68-1.27)$ & $1.01(0.80-1.27)$ & $1.10(0.87-1.38)$ & 0.70 & 0.61 \\
\hline DRB1*07:01 & 12.8 & $0.96(0.70-1.32)$ & $1.04(0.84-1.29)$ & $1.01(0.83-1.23)$ & 0.90 & 0.84 \\
\hline DRB1*15:01 & 13.1 & $0.73(0.57-0.94)$ & $0.78(0.65-0.95)$ & $0.88(0.72-1.07)$ & 0.03 & 0.43 \\
\hline$D Q A 1 * 01: 01$ & 14.9 & $1.08(0.83-1.42)$ & $1.03(0.84-1.26)$ & $0.88(0.73-1.06)$ & 0.42 & 0.27 \\
\hline DQA1*01:02 & 19.1 & $0.77(0.62-0.95)$ & $0.83(0.71-0.99)$ & $0.90(0.76-1.06)$ & 0.06 & 0.53 \\
\hline$D Q A 1 * 01: 03$ & 6.9 & $1.20(0.84-1.73)$ & $0.99(0.75-1.31)$ & $0.83(0.64-1.07)$ & 0.38 & 0.35 \\
\hline$D Q A 1 * 02: 01$ & 12.9 & $0.98(0.71-1.34)$ & $1.05(0.85-1.30)$ & $1.01(0.83-1.23)$ & 0.89 & 0.79 \\
\hline DQA1*03:01 & 18.4 & $0.87(0.68-1.12)$ & $0.96(0.80-1.15)$ & $1.11(0.93-1.32)$ & 0.44 & 0.26 \\
\hline$D Q A 1 * 05: 01$ & 25.1 & $1.31(1.06-1.62)$ & $1.17(1.01-1.37)$ & $1.16(1.00-1.34)$ & 0.01 & 0.91 \\
\hline$D Q B 1 * 02: 01$ & 18.3 & 1.14 (0.91-1.43) & $1.12(0.95-1.32)$ & $1.05(0.89-1.24)$ & 0.33 & 0.58 \\
\hline DQB1*03:01 & 18.4 & $1.06(0.82-1.36)$ & $1.06(0.89-1.27)$ & $1.14(0.97-1.33)$ & 0.21 & 0.59 \\
\hline$D Q B 1 * 03: 02$ & 10.7 & $0.86(0.63-1.17)$ & $1.00(0.80-1.25)$ & $1.04(0.85-1.29)$ & 0.90 & 0.79 \\
\hline$D Q B 1 * 05: 01$ & 12.1 & $1.03(0.76-1.39)$ & $1.00(0.80-1.25)$ & $0.86(0.70-1.06)$ & 0.38 & 0.32 \\
\hline$D Q B 1 * 06: 02$ & 12.6 & $0.70(0.54-0.91)$ & $0.78(0.64-0.95)$ & $0.89(0.73-1.09)$ & 0.03 & 0.37 \\
\hline$D Q B 1 * 06: 03$ & 6.4 & $1.19(0.82-1.73)$ & $1.00(0.75-1.33)$ & $0.81(0.62-1.06)$ & 0.33 & 0.29 \\
\hline DPA1*01:03 & 18.7 & $1.08(0.84-1.38)$ & $1.00(0.83-1.20)$ & $0.95(0.78-1.15)$ & 0.88 & 0.69 \\
\hline DPA 1*02:01 & 14.8 & $1.04(0.79-1.37)$ & $1.05(0.86-1.28)$ & $0.92(0.75-1.12)$ & 0.64 & 0.35 \\
\hline$D P B 1 * 02: 01$ & 13.3 & $1.11(0.84-1.46)$ & $1.07(0.87-1.30)$ & $1.25(1.05-1.50)$ & 0.03 & 0.24 \\
\hline DPB 1*03:01 & 10.4 & $1.02(0.76-1.38)$ & $1.04(0.84-1.30)$ & $0.67(0.53-0.86)$ & 0.007 & 0.009 \\
\hline DPB1*04:01 & 42.4 & $0.84(0.69-1.01)$ & $0.91(0.79-1.05)$ & $1.03(0.90-1.18)$ & 0.42 & 0.22 \\
\hline DPB1*04:02 & 11.2 & $1.37(1.02-1.83)$ & $1.15(0.93-1.42)$ & $1.05(0.84-1.30)$ & 0.38 & 0.55 \\
\hline rs9273349 T & 41.4 & $0.89(0.74-1.07)$ & $0.86(0.74-0.99)$ & $0.82(0.71-0.95)$ & 0.005 & 0.69 \\
\hline
\end{tabular}

Data are presented as OR $\left(95 \%\right.$ Cl) unless otherwise stated. AF: allele frequency. ${ }^{\text {* }}$ : weighted average in industrial cohorts, ESE and B58C; ๑ $\mathrm{n}=946 ;{ }^{+}: \mathrm{n}=2629 ;{ }^{\S}: \mathrm{n}=3396$. Bold face indicates $\mathrm{p}<0.05$.

As the majority of exposed subjects from the general population cohorts were exposed to latex, an additional sensitivity analysis was performed in ESE and B58C, by testing for gene-environment interaction in two mutually exclusive exposed groups: "ever being exposed to latex" and "ever being exposed to HMW allergens, but never to latex", with unexposed as a reference group (tables E4 and E5). The geneenvironment interaction between $D P B 1^{*} 03: 01$ and overall HMW exposure was only observed in latex exposed versus unexposed subjects (interaction $\mathrm{p}=0.01$ ). As a result, in ESE subjects carrying at least one $D P B 1^{\star} 03: 01$ allele, a strong association between latex exposure and adult-onset asthma was observed (OR 3.12, 95\% CI 1.73-5.65).

Association between the 18 tag SNPs in the HLA-II region and adult-onset asthma was similar in occupationally exposed and unexposed individuals (interaction $\mathrm{p}>0.05$; table E6).

\section{Discussion}

In a meta-analysis of European cohorts, we did not find evidence to suggest that common HLA-II alleles are associated with the risk of adult-onset asthma. However, when analyses were stratified by occupational HMW allergen exposure, the $D P B 1^{\star} 03$ :01 allele appeared to be negatively associated with adult-onset asthma in unexposed subjects, and an interaction was found between $D P B 1^{\star} 03: 01$ and exposure to latex. $D Q B 1^{\star} 06: 02$ showed a consistent inverse association with asthma in cohorts of bakery workers and agricultural workers, but not in the HMW allergen exposed subjects from the general population studies.

We showed that rs9273349, the SNP in the HLA-DQ region that emerged from the GABRIEL GWAS [4], influences adult-onset asthma to an equal extent in both HMW allergen exposed and occupationally unexposed individuals. Thus, no evidence was found to suggest that occupational allergen exposures might be involved in the association of rs9273349, or any of the other 18 selected tag SNPs in the HLA-II region, and adult-onset asthma. rs9273349 was significantly associated with adult-onset asthma in combined ESE and B58C studies (OR 0.82, $\mathrm{p}=0.002$ ). We also computed this association in the other GABRIEL adult 
cohorts that were not included in the present study because detailed occupational history information was not available, showing a similar result (OR 0.80, $\mathrm{p}=0.001)$. We have shown that rs9273349 is in a region of extended linkage disequilibrium (as indicated by $\mathrm{D}^{\prime}$ ) that includes $D R B 1, D Q A 1$ and $D Q B 1$, but not $D P A 1$ or $D P B 1$. However, none of the classical HLA-II alleles were strongly correlated with $\mathrm{rs} 9273349\left(\mathrm{r}^{2}=0.00-0.32\right.$; tables E2 and E3), and the rs9273349 association signal was not explained by the classical HLA-II alleles in multiple regression models. Despite the well described role of HLA-II molecules in allergen recognition, it is as yet unclear what the association of rs 9273349 with adult-onset asthma might mean. It could be speculated that this SNP might influence the level of expression of HLA molecules. Alternatively, non-HLA genes could play a role. The MHC is one of the most complicated regions of the human genome, with extensive linkage disequilibrium that extends across hundreds of HLA and non-HLA genes. Linkage and association between HLA variants and asthma may in part be due to association between nearby non-HLA genes (in linkage disequilibrium with HLA) and asthma, e.g. TNFA [33]. The latter explanation would imply a role for different mechanisms, which may also explain why we did not find an interaction between rs9273349 and occupational allergen exposure.

Our study population was large enough to reveal moderate associations between classical HLA-II alleles and adult-onset asthma, and the complete absence of marginal associations is probably not due to a lack of statistical power. When taking occupational exposure into account, carrying $D P B 1^{\star} 03: 01$ appeared to protect against adult-onset asthma among unexposed individuals. However, in ESE subjects carrying the $D P B 1^{\star} 03: 01$ allele, a strong positive association between exposure to latex and adult-onset asthma was observed $(\mathrm{OR}>3)$. This finding suggests that $D P B 1^{\star} 03: 01$ may confer an increased risk of developing asthma in adulthood, but only for those with specific workplace exposures. We can only speculate on the mechanism behind an opposite effect among the unexposed. A better protection against respiratory infections or the development of allergy to other antigens may be involved. A German case-control study investigated the role of $H L A-D Q$ and $H L A-D R$ (but not $H L A-D P$ ) among 269 health care workers with latex allergy and 90 nonatopic control subjects [34]. DRB1*04/DQB1*03:02 haplotype was associated with an increased risk of IgE to a major latex allergen (Hev b 6.02) [34]. We also found positive, but not significant, associations of $D R B 1^{*} 04: 01$ and $D Q B 1^{*} 03: 02$ with adult-onset asthma among our 1123 latex-exposed workers. Only a few other studies investigated HLA alleles in relation to asthma or allergic outcomes among workers exposed to HMW allergens, namely laboratory animal allergens [35], cow dander [36] and fish food [37]. $D Q B 1^{*} 06: 02$, which was here associated with asthma both in bakery workers and agricultural workers, did not emerge from these other studies.

Studying gene-environment interaction in large-scale studies has some inherent limitations. In populations sampled from the general population (or asthma patients and their families as in EGEA), there is a large heterogeneity in occupations and related exposures. The majority of workers who were classified as "exposed to HMW agents" are latex-exposed healthcare professionals who are typically exposed to other agents, such as cleaning products, that may cause asthma through a non-IgE mediated mechanism [38]. Despite the heterogeneity in exposures, associations between occupational exposure to HMW allergens and adult-onset asthma were comparable across cohorts and showed a significantly increased risk, which was similar in magnitude to earlier published associations $[15,16,19]$. In the present sample of B58C, the association of HMW exposure and asthma appeared to be weaker than the earlier published association in a larger sample of B58C [16]. This difference appeared to be due to chance variation, as the odds ratios did not differ significantly between the B58C samples with and without genotyping available.

The proportion of males among exposed subjects was lower in SAPALDIA (12\%) and ECRHS (14\%) than in EGEA (29\%) and B58C (33\%). In the ESE exposed group, association between $D P B 1^{\star} 03: 01$ and adultonset asthma was more pronounced in males ( $O R 2.71, p=0.055)$ than in females (OR 1.18, $\mathrm{p}=0.52$ ), but interaction was not significant $(\mathrm{p}=0.18)$ due to small sample size. This association did not differ between unexposed males and females in ESE. The workforce-based studies also differed from the population-based cohorts in terms of exposures, phenotype and proportion of male subjects. Therefore, we performed separate analyses in population-based cohorts only and in all exposed subjects. Also within the workforcebased cohorts, heterogeneity in source, nature and levels of allergen exposures exists. Bakery workers can be exposed to allergenic enzymes and flour allergens, but also to cleaning products, whereas agricultural workers (e.g. grain farmers and dairy farmers) may be exposed to allergens from animal danders, storage mites, grain and flour. Various other exposures in the agricultural environment, such as endotoxins and disinfectants, are also associated with (nonallergic) asthma. The association of $D Q B 1^{\star} 06: 02$ with asthma among bakers and farmers may provide further explanations why some of these workers develop respiratory health problems, while others with similar exposure levels remain healthy [39].

In this large-scale meta-analysis, we were not able to study specific IgE to occupational allergens (e.g. latex, wheat and $\alpha$-amylase) or clinically assessed occupational asthma as a phenotype. Instead, we used adult-onset 
asthma, which was consistently associated with HMW allergen exposure (fig. 1) and with rs9273349 in GWAS. We aimed to further investigate this HLA signal in GWAS and, therefore, we decided not to include other asthma phenotypes or atopic sensitisation in the present study. Although a substantial part of adult-onset asthma is attributable to occupational exposures, other risk factors, triggers and comorbid conditions such as smoking, female sex hormones, respiratory infections and obesity are also associated with the development of asthma in adulthood [40]. The relevance of HLA-II to most of these determinants is, however, less obvious.

In conclusion, imputed common HLA-II alleles were not associated per se with adult-onset asthma in a meta-analysis of European cohorts. However, when taking occupational allergen exposures into account, results showed a negative association between $D P B 1^{\star} 03: 01$ and adult-asthma in the unexposed, and suggested a gene-environment interaction between the $D P B 1^{\star} 03: 01$ allele and exposure to latex. Furthermore, $D Q B 1^{\star} 06: 02$ was associated with asthma among bakery workers and agricultural workers, suggesting a role for specific occupational allergens. Occupational HMW allergen exposures did not modify the association between rs9273349, the SNP in the HLA-DQ region that emerged from the GABRIEL GWAS, and adult-onset asthma.

\section{Acknowledgements}

The author's affiliations are as follows. Lidwien A.M. Smit: Division of Environmental Epidemiology, Institute for Risk Assessment Sciences (IRAS), Utrecht, The Netherlands; David P. Strachan: Division of Population Health Sciences and Education, St George's University of London, London, UK; Roel Vermeulen: Division of Environmental Epidemiology, Institute for Risk Assessment Sciences (IRAS), and Julius Center for Health Sciences and Primary Care, University Medical Center Utrecht, Utrecht, The Netherlands; Paul I.W. de Bakker: Julius Center for Health Sciences and Primary Care, and Institute for Molecular Medicine, University Medical Center Utrecht, Utrecht, The Netherlands; Florence Demenais: INSERM, U946, and Université Paris Diderot, Sorbonne Paris Cité, Institut Universitaire d'Hématologie, Paris, France; Orianne Dumas: INSERM, Centre for Research in Epidemiology and Population Health (CESP), U1018, Respiratory and Environmental Epidemiology Team, and Université Paris Sud 11, UMRS 1018, Villejuif, France; Anne-Elie Carsin: Centre for Research in Environmental Epidemiology (CREAL), Municipal Institute of Medical Research (IMIM-Hospital del Mar), and CIBER Epidemiologia y Salud Pública (CIBERESP), Barcelona, Spain; Paul Cullinan: Dept of Occupational and Environmental Medicine, National Heart and Lung Institute, Imperial College, London, UK; Ivan Curjuric: Swiss Tropical and Public Health Institute, and University of Basel, Basel, Switzerland; Rebecca E. Ghosh: Respiratory Epidemiology and Public Health Group, National Heart and Lung Institute, and Small Area Health Statistics Unit, MRC-PHE Centre for Environment and Health, Imperial College, London, UK; Dick Heederik: Division of Environmental Epidemiology, Institute for Risk Assessment Sciences (IRAS), Utrecht, The Netherlands; Medea Imboden: Swiss Tropical and Public Health Institute, and University of Basel, Basel, Switzerland; Deborah Jarvis: Respiratory Epidemiology and Public Health Group, National Heart and Lung Institute, Imperial College, London, UK; Mark Lathrop: Commissariat à l'Energie Atomique, Institut de Génomique, Centre National de Génotypage (CNG), Evry, France, and McGill University, Montreal, QC, Canada; Nicole Le Moual: INSERM, Centre for Research in Epidemiology and Population Health (CESP), U1018, Respiratory and Environmental Epidemiology Team, and Université Paris Sud 11, UMRS 1018, Villejuif, France; Amar Mehta: Swiss Tropical and Public Health Institute, and University of Basel, Basel, Switzerland, and Harvard School of Public Health, Dept of Environmental Health, Boston, MA, USA; David Miedinger: University of Basel, Basel, and Swiss Accident Insurance Fund (Suva), Lucerne, Switzerland; Torben Sigsgaard: Dept of Environmental and Occupational Medicine, Aarhus University, Aarhus, Denmark; Valérie Siroux: INSERM, U823, and Université Joseph Fourier, Grenoble, France; David Vernez: Institute for Work and Health, Lausanne, Switzerland; Jan Paul Zock: Centre for Research in Environmental Epidemiology (CREAL), CIBER Epidemiologia y Salud Pública (CIBERESP), and Universitat Pompeu Fabra (UPF), Barcelona, Spain; Francine Kauffmann: INSERM, Centre for Research in Epidemiology and Population Health (CESP), U1018, Respiratory and Environmental Epidemiology Team, and Université Paris Sud 11, UMRS 1018, Villejuif, France; Nicole Probst-Hensch: Swiss Tropical and Public Health Institute, and University of Basel, Basel, Switzerland; Manolis Kogevinas: Centre for Research in Environmental Epidemiology (CREAL), Municipal Institute of Medical Research (IMIM-Hospital del Mar), and CIBER Epidemiologia y Salud Pública (CIBERESP), Barcelona, Spain, and National School of Public Health, Athens, Greece; Emmanuelle Bouzigon: INSERM, U946, and Université Paris Diderot, Sorbonne Paris Cité, Institut Universitaire d'Hématologie, Paris, France.

We are grateful to all study members and staff involved in data collections in each cohort. For the 1958 Birth Cohort, the asthma-specific job-exposure matrix was applied with an expert re-evaluation step by UK experts in occupational lung disease (Paul Cullinan, David Fishwick (Centre for Workplace Health, Sheffield, UK), Jennifer Hoyle (North Manchester General Hospital, Manchester, UK) and Chris Warburton (North Manchester General Hospital, Manchester, UK)). Further acknowledgements are given in the online supplementary material.

\section{References}

Vercelli D. Discovering susceptibility genes for asthma and allergy. Nat Rev Immunol 2008; 8: 169-182.

Howell WM, Holgate ST. HLA genetics and allergic disease. Thorax 1995; 50: 815-818.

Kauffmann F, Castro-Giner F, Smit LAM, et al. Gene-Environment Interactions in Occupational Asthma. In: Sigsgaard T, Heederik D, eds. Occupational Asthma. basel, Birkhauser Publishing, 2010; pp. 205-228.

4 Moffatt MF, Gut IG, Demenais F, et al. A large-scale, consortium-based genomewide association study of asthma. N Engl J Med 2010; 363: 1211-1221.

5 Li X, Howard TD, Zheng SL, et al. Genome-wide association study of asthma identifies RAD50-IL13 and HLA-DR/ DQ regions. J Allergy Clin Immunol 2010; 125: 328-335. 
6 Lasky-Su J, Himes BE, Raby BA, et al. HLA-DQ strikes again: genome-wide association study further confirms HLA-DQ in the diagnosis of asthma among adults. Clin Exp Allergy 2012; 42: 1724-1733.

7 Granada M, Wilk JB, Tuzova M, et al. A genome-wide association study of plasma total IgE concentrations in the Framingham Heart Study. J Allergy Clin Immunol 2012; 129: 840-845.

8 Noguchi E, Sakamoto H, Hirota T, et al. Genome-wide association study identifies HLA-DP as a susceptibility gene for pediatric asthma in Asian populations. PLoS Genet 2011; 7: e1002170.

9 Levin AM, Mathias RA, Huang L, et al. A meta-analysis of genome-wide association studies for serum total IgE in diverse study populations. J Allergy Clin Immunol 2013; 131: 1176-1184.

10 Ramasamy A, Curjuric I, Coin LJ, et al. A genome-wide meta-analysis of genetic variants associated with allergic rhinitis and grass sensitization and their interaction with birth order. J Allergy Clin Immunol 2011; 128: 996-1005.

11 Bonnelykke K, Matheson MC, Pers TH, et al. Meta-analysis of genome-wide association studies identifies ten loci influencing allergic sensitization. Nat Genet 2013; 45: 902-906.

12 Vercelli D. Remembrance of things past: HLA genes come back on the allergy stage. J Allergy Clin Immunol 2012; 129: 846-847.

13 Bouzigon E, Corda E, Aschard $\mathrm{H}$, et al. Effect of 17q21 variants and smoking exposure in early-onset asthma. N Engl J Med 2008; 359: 1985-1994.

14 Kauffmann F, Demenais F. Gene-environment interactions in asthma and allergic diseases: challenges and perspectives. J Allergy Clin Immunol 2012; 130: 1229-1240.

15 Kogevinas M, Zock JP, Jarvis D, et al. Exposure to substances in the workplace and new-onset asthma: an international prospective population-based study (ECRHS-II). Lancet 2007; 370: 336-341.

16 Ghosh RE, Cullinan P, Fishwick D, et al. Asthma and occupation in the 1958 birth cohort. Thorax 2013; 68: 365-371.

17 Toren K, Blanc PD. Asthma caused by occupational exposures is common - a systematic analysis of estimates of the population-attributable fraction. BMC Pulm Med 2009; 9: 7-2466-9-7.

18 Kauffmann F, Dizier MH, Pin I, et al. Epidemiological study of the genetics and environment of asthma, bronchial hyperresponsiveness, and atopy: phenotype issues. Am J Respir Crit Care Med 1997; 156: S123-S129.

19 Kennedy SM, Le Moual N, Choudat D, et al. Development of an asthma specific job exposure matrix and its application in the epidemiological study of genetics and environment in asthma (EGEA). Occup Environ Med 2000; 57: 635-641.

20 Downs SH, Schindler C, Liu LJ, et al. Reduced exposure to PM10 and attenuated age-related decline in lung function. N Engl J Med 2007; 357: 2338-2347.

21 Mehta AJ, Miedinger D, Keidel D, et al. Occupational exposure to dusts, gases, and fumes and incidence of chronic obstructive pulmonary disease in the Swiss Cohort Study on Air Pollution and Lung and Heart Diseases in Adults. Am J Respir Crit Care Med 2012; 185: 1292-1300.

22 European Community Respiratory Health Survey II Steering Committee. The European Community Respiratory Health Survey II. Eur Respir J 2002; 20: 1071-1079.

23 Imboden M, Bouzigon E, Curjuric I, et al. Genome-wide association study of lung function decline in adults with and without asthma. J Allergy Clin Immunol 2012; 129: 1218-1228.

24 Strachan DP, Rudnicka AR, Power C, et al. Lifecourse influences on health among British adults: effects of region of residence in childhood and adulthood. Int J Epidemiol 2007; 36: 522-531.

25 Basinas I, Schlunssen V, Heederik D, et al. Sensitisation to common allergens and respiratory symptoms in endotoxin exposed workers: a pooled analysis. Occup Environ Med 2012; 69: 99-106.

26 Jacobs JH, Meijster T, Meijer E, et al. Wheat allergen exposure and the prevalence of work-related sensitization and allergy in bakery workers. Allergy 2008; 63: 1597-604.

27 Barrett JC, Fry B, Maller J, et al. Haploview: analysis and visualization of LD and haplotype maps. Bioinformatics 2005; 21: 263-265.

28 International HIV Controllers Study., Pereyra F., et al. The major genetic determinants of HIV-1 control affect HLA class I peptide presentation. Science 2010; 330: 1551-1557.

29 Nejentsev S, Howson JM, Walker NM, et al. Localization of type 1 diabetes susceptibility to the MHC class I genes HLA-B and HLA-A. Nature 2007; 450: 887-892.

30 Smit LA, Kogevinas M, Anto JM, et al. Transient receptor potential genes, smoking, occupational exposures and cough in adults. Respir Res 2012; 13: 26-9921-13-26.

31 Kraft P, Yen YC, Stram DO, et al. Exploiting gene-environment interaction to detect genetic associations. Hum Hered 2007; 63: 111-119.

32 Aschard H, Hancock DB, London SJ, et al. Genome-wide meta-analysis of joint tests for genetic and geneenvironment interaction effects. Hum Hered 2010; 70: 292-300.

33 Munthe-Kaas MC, Carlsen KL, Carlsen KH, et al. Dr-Dq haplotypes and the TNFA-308 polymorphism: associations with asthma and allergy. Allergy 2007; 62: 991-998.

34 Rihs HP, Chen Z, Rueff F, et al. HLA-DQ8 and the HLA-DQ8-DR4 haplotype are positively associated with the hevein-specific IgE immune response in health care workers with latex allergy. J Allergy Clin Immunol 2002; 110: 507-514.

35 Jeal H, Draper A, Jones M, et al. HLA associations with occupational sensitization to rat lipocalin allergens: a model for other animal allergies? J Allergy Clin Immunol 2003; 111: 795-799.

36 Kauppinen A, Perasaari J, Taivainen A, et al. Association of HLA class II alleles with sensitization to cow dander Bos d 2, an important occupational allergen. Immunobiology 2012; 217: 8-12.

37 Tautz C, Rihs HP, Thiele A, et al. Association of class II sequences encoding DR1 and DQ5 specificities with hypersensitivity to chironomid allergen Chi t I. J Allergy Clin Immunol 1994; 93: 918-925.

38 Dumas O, Donnay C, Heederik DJ, et al. Occupational exposure to cleaning products and asthma in hospital workers. Occup Environ Med 2012; 69: 883-889.

39 Smit LA. Respiratory health effects in agricultural workers: are some more susceptible than others? Expert Rev Respir Med 2012; 6: 7-10.

40 de Nijs SB, Venekamp LN, Bel EH. Adult-onset asthma: is it really different? Eur Respir Rev 2013; 22: 44-52. 